\title{
AS EPÍSTOLAS DE MÁRIO DE ANDRADE E CARLOS DRUMMOND DE ANDRADE: ESCRITURA, ESCRITOR E TEXTO
}

\section{MÁRIO DE ANDRADE AND CARLOS DRUMMOND DE ANDRADE'S EPISTLES: WRITING, WRITER AND TEXT}

\author{
Manuel Veronez \\ Universidade Estadual de Ponta Grossa
}

\begin{abstract}
Resumo: Este artigo apresenta a noção de escritura proposta por Roland Barthes (1986), além das noções de texto e de escritor. Articulado a essas três noções, vê-se, também, seus opostos em relação dicotômica respectivamente: escrevência, obra e escrevente. Em seguida, é apresentada uma explanação sobre a história das missivas no contexto da escrita de si assim como sua forma peculiar de manifestação e de representação. A partir dessa ambientação, tenta-se recolocar a escritura, o texto e o escritor propostos por Barthes $(1986,1996)$ articulados às cartas privadas trocadas entre Mário de Andrade e Carlos Drummond de Andrade, com o intuito de mostrar que é possível trabalhar com essas três noções barthesianas para além do texto literário, estendendo, em certa medida, para textos não literários, como as missivas em questão.
\end{abstract}

Palavras-chave: Cartas privadas. Escrita de si. Texto. Escritor. Escritura.

\begin{abstract}
This article presents the notion of writing proposed by Roland Barthes (1986), in addition to the notions of text and writer. Articulated to these three notions, it can also be observed their opposites in a dichotomous relationship, respectively: inscription, work and scriptor. Then, an explanation of the history of missives in the context of self writing is presented, as well as their peculiar way of manifestation and representation. Based on this ambiance, an attempt is made to replace the writing, text and writer proposed by Barthes $(1986,1996)$ articulated to the private letters exchanged between Mário de Andrade and Carlos Drummond de Andrade, in order to show that it is possible to work with these three Barthesian notions beyond the literary text, extending, to some extent, to non-literary texts, such as the missives in question.
\end{abstract}

Keywords: Private letters. Self writing. Text. Writer. Writing.

* Doutor em Estudos Linguísticos pela Universidade Federal de Uberlândia (UFU), com período sanduíche na Université ParisSorbonne (Paris IV). Professor Colaborador na Universidade Estadual de Ponta Grossa (UEPG). ORCID: https://orcid.org/00000002-8777-9859. E-mail: <veronezmanuel@gmail.com>. 


\section{Introdução}

Quanto mais uma história é contada de uma maneira decente, eloqüente, sem malícia, num tom adocicado, tanto mais fácil é invertê-la, enegrecê-la, lê-la às avessas (Mme de Ségur lida por Sade). Esta inversão, sendo uma pura produção, desenvolve soberbamente o prazer do texto.

(Roland Barthes)

Veremos, neste artigo, em um primeiro momento, as noções de texto, de escritura e de escritor que Roland Barthes $(1986,1996)$ postula em seus textos, O grau zero da escritura e O prazer do texto. Em um segundo momento, observaremos as características da escrita de si presentes no gênero epistolar e um pouco de sua história; e, em um terceiro e último momento, proporemos uma inter-relação entre as noções de texto, de escritura e de escritor barthesianas e as cartas privadas trocadas entre Mário de Andrade e Carlos Drummond de Andrade, com o intuito de mostrar que as epístolas dos Andrades podem funcionar como textos produzidos por escritores e engendrados a partir de escrituras específicas, embora não sejam textos estritamente literários.

De acordo com Barthes (1996), para conceber um texto, deve haver o engajamento com a linguagem, ou seja, deve-se ser fiel e preocupado com aquilo que a linguagem tem a oferecer e a mostrar. Nessa perspectiva, a única forma possível para perceber o que a linguagem tem a oferecer e a mostrar, segundo o autor, é por meio do seu caráter ilimitado, no momento em que o texto é lido e se percebe que ele não se fecha, não se isola, não se delimita prontamente.

Dessa maneira, podemos observar a ideia de colocarmos em pé de igualdade o ler e o escrever. Dito de outro modo, é no processo de leitura que se escreve e/ou se reescreve o texto lido, delineando a fruição e o verdadeiro prazer do texto que, de alguma forma, está no abalo da gramática, na subversão, no texto social e atópico, na desideologização do discurso. Para Barthes (1996), esse processo é possível somente na linguagem da arte, ou seja, na linguagem literária, não sendo possível realizar-se em textos não literários. No entanto, tentaremos mostrar, em certa medida e dada algumas condições, que é sim possível estabelecer esse processo também em textos não literários, como as epístolas em questão.

Barthes (1996) faz uma importante diferenciação entre texto e obra, em que delimita esta como matéria e aquele como materialidade, isto é, o texto não é fechado em sua significação própria e particular, ele é sempre inacabado, não esgotado. Não encontramos no texto apenas uma ideia ou um fim retórico convencido, como se vê na obra. Tudo que o texto tem a obra terá em seu oposto, em seu contrário. Em outras palavras, o texto é contexto, é possibilidade; e a obra é imposição, é o ato inabalado.

O texto, segundo Barthes (1986), é escritura e é feito pelo escritor, ao passo que a obra é escrevência e é feita pelo escrevente. O escrever da escritura se encontra na intransitividade, uma vez que não há uma finalidade objetiva para a língua, é a linguagem literária em que o escritor usa a palavra como perspectiva, cujas afirmações são interrogações infindas a todo o tempo. A escritura é a ocasião que está entre a língua e o estilo.

A língua, desse modo, é o objeto social, de formação de sociedades, de grupos sociais, de traço exterior, que carrega consigo, quando mobilizada, uma ilusória definição segura das coisas, 
um cerceamento, um limite ao que se refere ou ao que tenta se referir. A língua, nesse sentido, dá a falsa sensação de organização e de controle, sendo apenas “[...] um horizonte humano que instala ao longe uma certa familiaridade” (BARTHES, 1996, p. 121, grifo do autor). A língua é um horizonte que consegue, ou tenta conseguir, abarcar tudo (utopicamente falando, devido à sua natureza lacunar e não totalizante).

O estilo, por sua vez, se apresenta de forma mais introspectiva, em uma movimentação verticalizada, indo ao íntimo do escritor, mergulhada "[...] na lembrança fechada da pessoa” (BARTHES, 1996, p. 123), em que o escritor vê e interpreta seu próprio passado e sua história singular, tendo parte de sua identidade e de sua marca compartilhada ou transformada com a língua, no ato da escrita, mostrando diferentes e possíveis visões de um determinado objeto, tradicional ou não. Para Barthes (1996, p. 123), portanto, o “[...] estilo não passa de metáfora”.

O escrever da escrevência, todavia, em dicotomia com a escritura, se fixa na transitividade, visto que há uma finalidade para a língua, é a linguagem do crítico, do jornalista, do cientista etc., em que o escrevente usa a palavra apenas como instrumento de comunicação e de convencimento, cujo sentido busca se mostrar uno e limitado.

A escritura, em contrapartida, sendo um texto, é abordada como uma função, ou seja, ela é a relação entre criação (estilo) e sociedade (língua), é a linguagem literária que transforma e ressignifica as ideias da sociedade, sejam elas tradicionais ou não, apreendida "[...] na sua intenção humana e ligada assim às grandes crises da História” (BARTHES, 1996, p. 125). Desse modo, a partir do que foi apresentado alhures, buscaremos sustentar a hipótese de que as noções de texto, de escritura e de escritor, postuladas por Barthes (1986, 1996), podem, também, ser mobilizadas nas epístolas de Mário de Andrade e de Carlos Drummond de Andrade, isto é, em textos que não são estritamente literários. Mesmo compreendendo que essas três noções barthesianas em si propõem uma maneira de pensarmos a Literatura em uma relação entre recorte social e trabalho singular com a linguagem, buscaremos transpô-las e estendê-las a gêneros não exclusivamente literários, como o gênero epistolar, por exemplo.

\section{Sobre a escrita de si das missivas}

No caso da narrativa epistolar de si próprio, trata-se de fazer coincidir o olhar do outro e aquele que se volve para si próprio quando se aferem as acções quotidianas às regras de uma técnica de vida.

(Michel Foucault)

A prática da escrita de si tem uma relação entre a produção da subjetividade e a escrita propriamente, pois “[...] a escrita performa a noção de sujeito” (KLINGER, 2007, p. 27). Embora ela tenha se arraigado na cultura burguesa da Ilustração, a escrita de si não nasceu da Reforma nem do Romantismo, dado que é uma das práticas de escrita mais antigas do Ocidente e é uma atividade já observada em Santo Agostinho, por exemplo, que apresentava suas Confissões (AGOSTINHO, 2004) por meio dessa tradição de escrita autorreferencial. No seu início, a escrita de si, segundo Foucault, tinha “[...] um papel muito próximo do da confissão ao director, 
[...], que dev[ia] revelar, sem excepção, todos os movimentos da alma (omnes cogitationes)" (FOUCAULT, 1992, p. 131).

Na Antiguidade greco-romana, o “eu”, segundo Foucault (1992), em uma prática de escrita autorreferencial, era uma forma de estabelecer a escrita de si para contribuir, especificamente, na formação de si, ou seja, no cuidar-se de si, no treinamento de si por si mesmo, em que a escrita desempenhou um papel fundamental para si e, também, para o outro. De acordo com o autor, “[...] a escrita aparece regularmente associada à "meditação", [...], reflecte sobre eles, os assimila, e se prepara assim para enfrentar o real” (FOUCAULT, 1992, p. 133). Assim, a escrita como prática subjetiva, moldada e controlada pelo pensamento, forma a elaboração de discursos, de ideias e de visões que são aceitas e reconhecidas como "verdadeiras" nos processos racionais de ação.

Foi entre os séculos I e II que a escrita de si se apresentou de duas formas relevantes: os hypomnêmata e a correspondência. Segundo Foucault (1992, p. 134), Plutarco afirmava que a correspondência apresentava uma escrita etopoiética, quer dizer, tinha "[...] um operador da transformação da verdade em ethos". Os hypomnêmata eram espécies de cadernetas individuais em que se anotavam citações, reflexões e pensamentos ouvidos da boca de alguém ou encontrados em algum lugar específico, como livros, ditados orais e locais, fragmento de obras etc., que "[...] eram oferecidos como tesouro acumulado para a releitura e meditação posteriores" (KLINGER, 2007, p. 28). Contudo, os hypomnêmata não podem ser considerados substitutos da memória, mas devem ser vistos como um material e um meio para exercitar a prática de leitura, de releitura e de meditação.

Antes de tudo, lia-se, relia-se, meditava-se e dialogava-se com esses retalhos de discursos consigo mesmo, para depois ir em busca das opiniões dos outros, embora, a priori, essas cadernetas não tivessem uma narrativa de si, como os diários da literatura cristã, as cartas, os testemunhos, os depoimentos e os discursos memorialísticos. Os diários da literatura cristã, por exemplo, tinham um valor de purificação, que era concebida no momento da escrita íntima, confessional, própria de si e sobre si. Os hypomnêmata, portanto, procuravam "[...] captar o já dito; reunir aquilo que se pôde ouvir e ler, e isto com uma finalidade que não é nada menos que a constituição de si” (FOUCAULT, 1992, p. 137).

A correspondência, por sua vez, apresenta um caráter específico e típico de escrita de si, imediatamente percebida ao longo de sua construção histórica, pois consegue operar com a reflexão pessoal destinando-a ao outro, ou seja, há um remetente e um destinatário estabelecidos que, no momento próprio da ação de cada um, seja na escrita e/ou na leitura da missiva, estarão lendo e escrevendo em uma espécie de treino autorreflexivo de si e sobre si. De acordo com Foucault (1992, p. 145): "A carta enviada actua, em virtude do próprio gesto da escrita, sobre aquele que a envia, assim como actua, pela leitura e a releitura, sobre aquele que a recebe”.

Ao mesmo tempo em que o missivista apresenta determinado conselho a um problema de um amigo interlocutor, por exemplo, já se faz ele próprio também aconselhado, caso algum dia passe por essa mesma ou semelhante ocasião. Dessa maneira, percebe-se que esse tipo de escrita de si vai além do adestramento de si próprio pela escrita, através dos conselhos dados ao outro. Em outras palavras, a escrita de si das missivas manifesta a si próprio bem como ao outro.

Outra característica marcante e própria desse tipo de prática de escrita de si das cartas é a capacidade e a possibilidade que o eu epistolar (quem escreve) tem de tornar-se presente 
e/ou ausente para o seu interlocutor (quem lê), em um movimento racionalizado, recortado e interessado, sabendo ele, o missivista, o momento adequado de aproximar-se (apresentar-se) ou afastar-se (ausentar-se) do receptor epistolar, dependendo, sempre, da ocasião e do tema da missiva. De acordo com Foucault (1992):

Por meio da missiva, abrimo-nos ao olhar dos outros e instalamos o nosso correspondente no lugar do deus interior. Ela é uma maneira de nos darmos ao olhar do qual devemos dizer a nós próprios que penetra até ao fundo do nosso coração (in pectus intimum introspicere) no momento em que pensamos. (FOUCAULT, 1992, p. 151).

Assim, para o autor francês: “Escrever é pois 'mostrar-se’, dar-se a ver, fazer aparecer o rosto próprio junto ao outro” (FOUCAULT, 1992, p. 150), abrindo brechas para uma observação e reflexão crítica de si mesmo sobre si mesmo e do outro sobre si, o que é denominado pelo autor de introspecção.

\title{
Mário, Drummond e suas cartas privadas: escritor, escritura e texto
}

\author{
Responda, discuta, aceite ou não aceite, responda. Amigo eu serei sempre \\ de qualquer forma. Não é a amizade e a admiração que diminuirão, é a \\ qualidade delas. Amizade triste ou amizade alegre e do mesmo jeito a \\ admiração. Desculpe esta longuidão de carta. Eu sofro de \\ gigantismo epistolar.
}

(Mário de Andrade)

Alguns autores consagrados de várias áreas do conhecimento, ou suas próprias famílias, autorizaram a publicação de suas cartas privadas, as quais foram escritas a diferentes destinatários. Entretanto, há autores ou familiares que fizeram imposições para que elas viessem a público, como foi o caso das cartas privadas de Mário de Andrade, por exemplo. De acordo com ele, somente após a morte de todos os envolvidos, direta e indiretamente, sendo remetentes ou destinatários, e depois de passados 50 anos da morte de todos os envolvidos nas cartas, é que elas poderiam vir a público, estar na mão de quem as desejasse. Todavia, isso não foi seguido à risca em sua totalidade.

Diante disso, o que surge para nós, pesquisadores, como ideia é uma defesa - colaborada por Santiago (2006) - de que um texto produzido e publicado por meio do gênero epistolar, e por autores renomados da sociedade, não pertenceria a ninguém, pois autores e leitores, em certa medida, colocam suas marcas, complementam-se, ou até mesmo alteram o todo do texto, nunca o limitando ou o fechando em um significado único. Isso, de certo modo, vai de encontro às noções de texto, de escritor e de escritura postuladas por Barthes $(1986,1996)$ e já apresentadas anteriormente.

É por essa razão, ainda sustentado por Santiago (2006), que concebemos esses tipos de cartas como diálogos cara a cara (tête-à-tête), eu e tu, e, ao mesmo tempo, como diálogos para 
todos (pour tous), nos quais toda a essência dos escritores envolvidos se manifesta por meio do processo de escritura engendrado por eles. Nessa perspectiva, os escritores vão se construindo de várias maneiras e intenções possíveis, nunca da mesma forma.

No prefácio da compilação das cartas completas trocadas entre Mário de Andrade e Carlos Drummond de Andrade, por exemplo, Santiago (2002) assevera o seguinte ao leitor, nos dando indícios de comprovação para sustentarmos que as cartas dos Andrades mobilizam as noções barthesianas de texto, de escritura e de escritor, devido aos seus caráteres fluidos e em abertos:

Esta introdução à leitura delas não deve ser tomada ao pé da letra. Eu as fiz estrategicamente minhas, para que você, leitor, não se amedrontasse ao querer fazê-las suas. Pela edição em livro todos temos direito sobre elas. Cumpre a você julgar esta introdução como um passo firme e oscilante, precário, de alguém que teve a sorte de ser o primeiro estranho a aventurar-se pela caverna da correspondência privada. (SANTIAGO, 2002, p. 33, grifo do autor).

Ao analisarmos as cartas privadas de Mário de Andrade trocadas com Carlos Drummond de Andrade, percebemos que Mário busca construir uma escritura a partir de uma ambientação mais ampla e aberta das discussões, nunca fechada ou datada, deixando suas ideias fruírem no tecido dessa escritura, ou seja, naquilo que é "[...] essencialmente a moral da forma, é a escolha do domínio social no seio do qual o escritor decide situar-se na Natureza de sua linguagem" (BARTHES, 1996, p. 125), atravessada pelo manto do texto e guiada pela figura do escritor.

No interior das epístolas de Mário de Andrade e de Carlos Drummond de Andrade, é a escritura engendrada por eles, enquanto escritores, que os cria e os remonta no texto. Dessa forma, é a partir desse momento que a escritura deles também se faz presente e se apresenta aos leitores. Nesse sentido, a escritura passa a ser, no interior do texto epistolar, o corpo e a alma desses dois escritores.

Concebemos, assim, as cartas privadas de Mário e de Drummond enquanto terrenos abertos de experiências, de partilhas, de trocas e um lugar privilegiado na discussão nunca encerrada das ideias estéticas da linguagem literária da época, na qual buscam trabalhar essa linguagem e o texto por meio de provocações, de inconformidades e deixando brechas para que a mente e o raciocínio dos leitores cheguem, também, às infinitas possibilidades de interpretação.

As missivas dos Andrades são repletas de riquezas de significações no interior do mecanismo social, que podem transmitir, por exemplo, diferentes ideias acerca do que se passou em determinado tempo e em determinada época da história. Essas cartas privadas são vistas, nessa perspectiva, como um "[...] documento sujeito à variabilidade de valores, ao sabor de gostos e épocas” (MORAES, 2007, p. 104). Em outras palavras, as epístolas dos escritores Mário e Drummond fundam-se como textos cujas escrituras se revelam variáveis, discutíveis, abertas e repletas de réplicas e tréplicas, que funcionam como uma prática social que busca constituir, à época, uma corrente estética literária ainda por se fazer - o modernismo brasileiro.

Nesse viés, em uma carta sem data, do ano de 1924, é possível percebermos a escritura questionadora de Mário de Andrade quando ele propõe a Carlos Drummond de Andrade a necessidade de construir-se uma identidade nacional por meio da literatura para, assim, se civilizarem, se tornarem criadores em vez de meros copiadores: “Nós só seremos civilizados em relação às civilizações o dia em que criarmos o ideal, a orientação brasileira. Então passaremos da fase do 
mimetismo pra fase da criação. E então seremos universais, porque nacionais” (ANDRADE, M. de, 2002, p. 71).

É possível percebermos, nessa carta de Mário, que ele não quer concernir sua escritura questionadora na sociedade vigente, ao contrário, ele quer, com sua escritura, repudiar tal sociedade para propor uma outra, não mais atuando sobre ela, mas antes, desativando aquilo mesmo que permitiria reafirmá-la.

Drummond, mesmo se posicionando como um discípulo de Mário, engendra, também, uma escritura questionadora em suas cartas, ao não concordar com a ideia proposta por Mário de buscar-se a nacionalização do Brasil por intermédio da literatura. Segundo Drummond, em carta de 30 de dezembro de 1924, o debate giraria mais em torno de como tornar-se brasileiro do que a necessidade em si de sê-lo.

[...] não chegamos a nenhum acordo, embora eu, praticamente, esteja a seu lado, e, recusando as suas teorias, aceito com entusiasmo as suas criações. Se não estou confuso, o nosso debate (será mesmo um debate?) gira em menos sobre a necessidade de ser brasileiro que sobre os meios de vir a sê-lo. (ANDRADE, C. D. de, 2002, p. 77).

A carta de Drummond de 6 de fevereiro de 1925 (ANDRADE, C. D. de, 2002), por exemplo, é um texto que se abre às possibilidades, pois engendra uma escritura de reconhecimento de que é preciso ampliar a perspectiva de si mesmo enquanto escritor para livrar-se de certas imposições da língua e assumir-se como um criador inacabado da sua própria linguagem poética, aquele que se encontra sempre na busca.

Ah! Quando penso que também eu andei a esmo pelos jardins passadistas, colhendo e cheirando flores gramaticais, e bancando atitudes de sabedoria! Pois veio o imprevisto e me expulsou do jardim. Você, com duas ou três cartas valentes acabou o milagre. Converteu-me à terra. Creio agora que, sendo o mesmo, sou outro pela visão menos escura e mais amorosa das coisas que me rodeiam. Respiro com força. Berro um pouco. Disparo. Creio que sou feliz! (ANDRADE, C. D. de, 2002, p. 95).

Observamos, também, nos textos epistolares de Mário e de Drummond, a mobilização de escrituras que interpelam os aspectos técnicos e estéticos da literatura da época, propondo expansões, audácias e reinterpretações na linguagem artística, no intuito de provocar atualizações. Na carta de 18 de fevereiro de 1925, enviada a Drummond, Mário manifesta um texto repleto de nuances dessa provocação ao polemizar sobre os preconceitos gramaticais ainda arraigados no homem culto brasileiro. Desse modo, esse texto de Mário de Andrade (2002) vai ao cerne da questão, construindo uma escritura articulatória entre a proposta de uma língua tipicamente brasileira e a naturalização daquilo que já havia sido desnaturalizado pela normatização prescritiva e preconceituosa da gramática-luso-padrão.

Nessa estrada me meti. Sei que tudo está por fazer. E o que é pior, sei que uma palavra brasileira empregada na escrita soa pra todos como exotismo, regionalismo, porque só como regionalismo exótico foi empregada até agora. Mas isso não é culpa do escritor que a não emprega mais assim, mas a adota como 
sua maneira regular de expressão. Nem é culpa da palavra também. A culpa vem do preconceito civil adquirido na leitura dos livros cultos. Se munheca soa mal depois dos 15 anos de idade é porque o sujeito da cidade, mocinho faceiro e enfeitado de um despotismo de preconceitos inconscientemente hipócritas, nunca leu munheca em Fialho ou Machado de Assis e por isso se bota a policiar a língua que fala pras melindrosas do assunto e mesmo pros colegas de Academia. (ANDRADE, M. de, 2002, p. 101, grifos do autor).

Mário de Andrade, nessa mesma carta, continuando o engendramento da escritura interpelativa sobre os aspectos técnicos e estéticos da literatura brasileira da época, analisa alguns poemas de Drummond. Desse modo, é possível verificarmos que o texto de Mário se estende à abertura das possibilidades, ao criticar o uso excessivo de artigos definidos e indefinidos pelo poeta mineiro em seus versos. Mário de Andrade (2002) defende, assim, no interior do processo de mobilização de uma escritura sempre questionadora, a ideia de que a língua portuguesa do Brasil já não utiliza mais com frequência uma linguagem repleta de definições e/ou indefinições marcadas pelos artigos, propondo suas supressões.

Você já escapa com naturalidade do um galicismo nos seus poemas. Mas nem sempre. Aliás procure evitar o mais possível os artigos tanto definidos como indefinidos. Não só porque evita galicismo e está mais dentro das línguas hispânicas como porque dá mais rapidez e força incisiva pra frase. (ANDRADE, M. de, 2002, p. 102, grifo do autor).

Outro fator que percebemos durante o processo de leitura das cartas privadas de Mário de Andrade enviadas a Carlos Drummond de Andrade, é que a escritura de seu texto se propõe sempre além das reflexões comuns sobre o que seria a literatura brasileira. Por exemplo, sua escritura revela a proposição de uma corrente literária brasileira pautada na ruptura, no abandono de técnicas e de princípios tradicionais, no incentivo à revolta contra a chamada Inteligência Nacional, isto é, os valores, os costumes e as ideias tradicionais que vigoravam na sociedade brasileira da época.

Além de questionadora, a escritura elaborada nas cartas de Mário de Andrade é, também, incômoda, não conformista, pois é possível observarmos a compreensão do escritor de que a proposta de revolução contra a Inteligência Nacional ainda não era suficiente, era preciso mais. Sua escritura, nesse sentido, traça o caminho de uma tomada de consciência, de que é preciso construir um pensamento intelectual propriamente brasileiro que se liberte das amarras das influências estrangeiras.

Nessa perspectiva, esses textos de Mário de Andrade se desdobram, por meio do processo de escritura questionadora e não conformista engendrada pelo autor, no momento em que propõem a reinterpretação e a ressignificação das ideias vindas de fora do país, no intuito de buscar a constituição de um ethos literário brasileiro, ou seja, uma espécie de voz própria, de tom representativo da literatura nacional.

A escritura questionadora de Carlos Drummond de Andrade, a qual constrói e mobiliza sua carta de 6 de outubro de 1925, é marcada por um texto que se estende em duas indagações: i) sobre a ortografia de algumas palavras da língua portuguesa, como aquelas de origem estrangeira que ainda permanecem, à época, escritas na ortografia estrangeira; e ii) sobre a questão 
da acentuação das palavras. A escritura de Drummond revela, assim, um texto descerrado na insatisfação e na inquietação sobre o assunto, provocando-o a apresentar alternativas que deem conta de transformar a linguagem tradicional para se alcançar uma espécie de abrasileiramento dessas palavras:

Estou inclinado a admitir como digno do respeito dos reformadores um único elemento, que vem a ser a plástica das palavras. Esta sim, se deve respeitar. Escrever orizonte é um pecado muito feio de que me penitencio em tempo. A questão é saber onde acaba a plástica e onde começa o chumaço. Porque o phy de physica não é carne, é chumaço. Agora física ou mesmo fízica é um bonito corpo que a gente vê com agrado. Outra dificuldade: tem gente que gosta de carnações repolhudas e outras que preferem as secas, espigadas. Vejo que sob este ponto de vista a questão é insolúvel. Simplificação respeitando o ar das palavras não dá um passo seguro. O corte tem que ser feito com outra orientação. Diga o nome dalgum livro bom, que ilumine a questão. Preciso também de tua opinião sobre o problema do acento (meu Deus! Será um problema?), quando é preciso e quando não é preciso e que história é essa do acento grave, tão usado pelo Manuel Bandeira nas Poesias? Outra coisa: em que é que você acha preferível a forma dize-lo à forma dizel-o? Dizêlo não será a melhor de todas? (ANDRADE, C, D. de, 2002, p. 146, grifos do autor).

Na carta sem data de 1924, notamos, também, que a escritura engendrada por Mário de Andrade busca derrubar e atravessar as barreiras da linguagem literária, dado o caráter informe de seu texto, ao analisar e criticar os aspectos rítmicos, temáticos e gramaticais de outros poemas de Carlos Drummond. Nesse sentido, por meio da prática de uma escritura questionadora, Mário procura discutir, nos poemas de Drummond, os sentidos produzidos pelos usos das preposições, dos artigos, dos substantivos, das ideias e dos temas propostos:

Mas como você ainda está muito inteligente de cabeça pra cair no lirismo, repare que há muita coisa que é contado com memória em vez de vivido com sensação evocada. Disso um tal ou qual elemento prosaico que diminui a variedade do verso livre porque o confunde com a prosa. Todos nós temos isso. Eu tomei o partido de escrever em prosa simplesmente, no meio dos versos, como aquele comentário inteligente (= da inteligência) que vem nas "Danças", ou o caso do coronel Leitão do "Noturno". Ou então metrifico ("Rola-Moça") pra não cair no verso prosaico. Metrificação ingênua, balbuciante primitiva, lírica. "Política”, “Construção”, "Religião”, "Nota social”, "Sentimental” são muito, muito bons. O "Orozimbo" é simplesmente admirável. "Construção” como forma é perfeito. No "Orozimbo” a piada do fim, não sei, não gosto muito disso. Tenho a impressão de que você escreveu aquilo só pra acabar. Pode ser que me engane. O "No meio do caminho” é formidável. É o mais forte exemplo que conheço, mais bem frisado, mais psicológico de cansaço intelectual. Como pratico com o Manuel Bandeira e o Luís Aranha, e eles comigo, mando-te os teus versos com algumas sugestões. Mas quero que eles voltem pra mim. Preciso deles em minha casa enquanto não se publicam. (ANDRADE, M. de, 2002, p. 72). 
Como já mostrado anteriormente, Drummond, na escritura de suas cartas, se revela um discípulo questionador, pois se abre às discussões, às correções e aos comentários, mas não os acata completamente. Desse modo, é possível observarmos que a concepção de uma escritura também questionadora é um atributo da linguagem do poeta mineiro. Na carta de 30 de dezembro de 1924, por exemplo, o texto de Carlos Drummond de Andrade desvela seu aspecto inacabado, ao engendrar uma escritura compreensiva, porém, autônoma, ao explicar que nem todas as problematizações levantadas em sua poesia por Mário foram assentidas:

Falarei agora nas minhas tentativas poéticas. Devolvo-lhe quase todos os versos: cortei apenas os que pareceram mais ordinários. Seguem ainda alguns que você não conhece, embora não sejam os últimos. Aceitei com infinito prazer as sugestões com que você honrou os meus trabalhos, e que demonstram leitura atenta e simpática. Não aprovei tudo, mas quase tudo. "Nota social” - 1) "O poeta chega na estação”. Você gostou da regência... Pois eu não gostei, e agora que peguei o erro, vou emendá-lo. Isto é modo de ver pessoalíssimo: correção ou incorreção gramatical. Sou pela correção. Ainda não posso compreender os seus curiosos excessos. Aceitar tudo o que nos vem do povo é uma tolice que nos leva ao regionalismo. Na primeira esquina do "me deixa" você encontra o Monteiro Lobato ou outro qualquer respeitável aproveitador comercial do Jeca. Há erros lindos, eu sei. Mas que diabo, a cultura!... E poesia é também cultura. 2) "Cometimentos": palavra feia, concordo. Mas não tenho outra. Condenei "Nossa Senhora - a Vida” ao fogo eterno. E agora, peço-lhe catar as pulgas dos versos novos. Não achando bom, risque; não achando perfeito, corrija. Eu ficarei grato. Até hoje não encontrei em nenhum homem de letras franqueza igual à sua. Muito, muito obrigado pelo seu acolhimento, pela sua franqueza e pela sua bondade! (ANDRADE, C. D. de, 2002, p. 81-82).

Percebemos, desse modo, no interior do processo de elaboração das escrituras concebidas pelos Andrades, a produção de textos que tendem ao infinito das interpretações, devido ao caráter aberto, não acabado, descerrado das possibilidades de leitura. As escrituras de Mário e de Drummond procuram discutir, criticar e analisar os aspectos da linguagem literária para se pensar uma literatura brasileira para além da tradição estabelecida da época.

A partir das análises, é possível afirmarmos, então, que Mário e Drummond são, ao mesmo tempo, escritores e leitores, os quais produziram e leram textos por meio de escrituras específicas que, além de transgredirem a rotina genérica do gênero epistolar, buscaram, também, transgredir a técnica, a estética e a ética da literatura brasileira vigente da época.

Enfim, as cartas privadas trocadas entre Mário de Andrade e Carlos Drummond de Andrade estão para além do funcionamento de uma carta íntima, pois elas funcionam como uma prática social que busca constituir e legitimar uma proposta de uma linguagem literária ainda por se fazer. Essas cartas, dessa maneira, podem ser articuladas às noções de texto e de escritura barthesianas, pois elas não se fecham na rotina genérica de um gênero epistolar (um lugar no qual remetentes e destinatários falariam apenas de suas intimidades). Por essa razão, as cartas dos Andrades, mesmo não sendo textos especificamente literários, estão para além da ideia barthesiana de escrevência e de obra, e Mário e Drummond estão para além da ideia de escreventes, se confirmando escritores, o que sustenta nossa hipótese. 


\section{Considerações finais}

As epístolas de Mário de Andrade e de Carlos Drummond de Andrade, assim como a noção de texto barthesiana, apresentam um caráter de materialidade, funcionando como um molde em que se fixaria o retrato. Já a escritura que se move no interior dessa materialidade é “o veículo de uma imagem” (MORAES, 2007, p. 105), cujas possibilidades e reflexões a respeito da construção de ideias para uma linguagem literária aberta e plural acontecem.

Mário concebia o gênero epistolar como um projeto pedagógico de discussões sobre a criação artística literária brasileira, o que nos leva a considerar que a maneira como ele abordava o processo de escritura de suas epístolas está longe de ser uma obra, em termos barthesianos, ou seja, uma escrevência fechada, acabada e absoluta em suas significações. Dessa maneira, a correspondência dos Andrades se encontra no "terreno movediço do desassossego" (MORAES, 2007, p. 222), quer dizer, do choque de ideias, da desconstrução, da desautomatização, da mudança dos paradigmas considerados certos e únicos.

As cartas privadas trocadas entre Mário e Drummond acumulam variadas informações e assuntos sem nenhuma ordenação, finalização e hierarquização aparentes. Nessas missivas, a narrativa é repleta de movimentos e de imagens, em que se apresenta um discurso multifacetado e laboriosamente construído. Essas cartas privadas, encaradas enquanto um processo e um exercício de escrita de si, de alguma maneira, abrem espaço para o estabelecimento de vínculos e para a criação de redes que podem contribuir para a compreensão de como a linguagem literária pode ser abordada sem se fechar em si mesma.

Dessa forma, no interior do processo de escrita de si das missivas de Mário de Andrade e de Carlos Drummond de Andrade, ao mesmo tempo em que um remetente se abre ao seu destinatário para se fazer conhecer, o destinatário também se encontra em aberto para com o seu remetente: um eu se abrindo para outro eu. Segundo Santiago (2002, p. 20), no prefácio do livro compilado das cartas privadas completas trocadas entre Mário e Drummond: "Se cada carta, isoladamente, tem duas direções, a correspondência trocada tem pelo menos quatro”.

Nessa passagem, Santiago (2002) explica que Drummond não se reconhece apenas pela abertura de si que foi oferecida a Mário, do mesmo modo, Mário não se reconhece somente pela abertura de si oferecida a Drummond. Ambos buscam reconhecer a si próprios por meio desse duplo caminho que a troca de cartas possibilita: Drummond também se reconhece pelo que Mário lhe oferece sobre si mesmo, assim como Mário também se reconhece pelo que Drummond lhe oferece sobre si mesmo. É o falar do eu, sobre si, para o outro, em que o outro também fala de si quando fala ao eu e consigo mesmo.

De acordo com Barthes (1986), o texto tem de provar que nos deseja, e a prova mais forte e convincente é a escritura, que se faz trabalhada pelo escritor. Essa escritura é a "[...] ciência das fruições da linguagem, seu kama-sutra” (BARTHES, 1986, p. 11), a qual estabelece apenas um tratado, a própria escritura, que apresenta uma realidade ambígua, pois nasce de uma inter-relação, uma “[...] confrontação do escritor com a sociedade” (BARTHES, 1986, p. 125).

A escritura, na relação entre língua, estilo, criação e sociedade, e “[...] por uma espécie de transferência mágica” (BARTHES, 1986, p. 125), atribuirá ao escritor determinada finalidade 
social aberta a interpretações, como no caso das cartas privadas trocadas entre Mário de Andrade e Carlos Drummond de Andrade.

Por essa razão, tentarmos encontrar uma linha condutória para as cartas de Mário e de Drummond, para estabelecermos um começo, um meio e um fim bem delineados, formatados e cronologicamente definidos, é uma tarefa impossível, pois não há possibilidades de encontrarmos, com segurança, um fio condutor dessas missivas. Se houvesse possibilidades, os fios condutores, segundo Santiago (2002), seriam fios de contradições e imprevistos. O autor, no prefácio às cartas reunidas e publicadas dos Andrades, ainda reitera:

A carta, por exemplo, tem algo a ver com a solidão. Solidão é palavra de amor. Sua leitura também. (Nossa solidão de leitor). Solidão é meio de conhecimento para Carlos e Mário. Portanto, tem também algo a ver com o desejo de comunicação. (O discípulo tanto precisa do mestre quanto o mestre do discípulo, pois aquele sem este não o é). Carlos é um náufrago no mar da vida, que emite pedidos de socorro, não a todo e qualquer, mas àquele que merece amizade e seja capaz de prestar auxílio. "Não me arrependo", escreve Carlos na sua segunda carta, "de lhe haver mandado o meu artigo sobre o finado Anatole France. Ele promoveu uma aproximação intelectual que me é muito preciosa”. A carta resposta aproxima, muito obrigado - e distancia, precisamos continuar a conversa. (SANTIAGO, 2002, p. 21, grifos do autor).

\section{Referências}

Agostinho, A. (Santo Agostinho). Confissões. São Paulo: Editora Nova Cultural, 2004. (Coleção Os Pensadores).

ANDRADE, C. D. de. Carlos e Mário: correspondência entre Carlos Drummond de Andrade - inédita - e Mário de Andrade. Rio de Janeiro: Bem-Te-Vi Produções Literárias, 2002.

BARTHES, R. Novos ensaios críticos - O grau zero da escritura. São Paulo: Cultrix, 1986.

BARTHES, R. O prazer do texto. São Paulo: Perspectiva, 1996.

FOUCAULT, M. O que é um autor?. Lisboa: Passagens/Veja Editora, 1992.

KLINGER, D. I. Escritas de si, escritas do outro: o retorno do autor e a virada etnográfica. Rio de Janeiro: 7Letras, 2007.

MORAES, M. A. de. Orgulho de jamais aconselhar: a epistolografia de Mário de Andrade. São Paulo: Editora da Universidade de São Paulo; FAPESP, 2007.

SANTIAGO, S. "Suas cartas, nossas cartas”. In: ANDRADE, C. D. de. Carlos e Mário: correspondência entre Carlos Drummond de Andrade - inédita - e Mário de Andrade. Rio de Janeiro: Bem-Te-Vi, 2002. p. 7-33. 
MANUEL VERONEZ

SANTIAGO, S. Ora (direis) puxar conversa!: ensaios literários. Belo Horizonte: Editora UFMG, 2006.

Recebido em: maio 2020.

Aceito em: jul. 2020. 